\title{
Synthesis of polymer-derived graphene/silicon nitride-based nanocomposites with tunable dielectric properties
}

\author{
Xifan WANG, Gabriela MERA, ${ }^{\dagger}$ Koji MORITA* and Emanuel IONESCU \\ Technische Universität Darmstadt, Institut für Materialwissenschaft, Jovanka-Bontschits-Strasse 2, D-64287 Darmstadt, Germany \\ *National Institute for Materials Science (NIMS), 1-2-1 Sengen, Tsukuba, Ibaraki 305-0047, Japan
}

\begin{abstract}
Within the present work, reduced-graphene oxide (rGO)/silicon nitride $\left(\mathrm{Si}_{3} \mathrm{~N}_{4}\right)$ nanocomposites were prepared upon pyrolysis of a graphene oxide (GO)-filled polysilazane. The novel preparative approach consists in the synthesis of the polysilazane in the presence of different concentrations of GO, yielding a homogeneous GO/polysilazane composite which was subsequently thermally converted in $\mathrm{Ar}$ atmosphere into $\mathrm{rGO} / \mathrm{Si}_{3} \mathrm{~N}_{4}$ nanocomposites. Hot-pressing of the obtained nanocomposite powders delivered monolithic $\mathrm{rGO} / \mathrm{Si}_{3} \mathrm{~N}_{4}$. All prepared samples exhibited the presence of homogeneously dispersed rGO phase within an amorphous or crystalline silicon nitride matrix, as for the as-prepared and hot-pressed samples, respectively. An increasing amount of rGO in the nanocomposites was found to gradually suppress the crystallization of the silicon nitride matrix into $\alpha$ $\mathrm{Si}_{3} \mathrm{~N}_{4}$. Moreover, depending on the volume fraction of the graphene phase in the ceramic nanocomposites, different dielectric properties were observed, indicating a facile preparative method to produce materials with tunable electromagnetic waves (EMW) behavior.
\end{abstract}

(C2016 The Ceramic Society of Japan. All rights reserved.

Key-words : Silicon nitride, Reduced graphene oxide (rGO), rGO/Si3N4, Polymer-derived ceramic nanocomposites, Dielectric properties

\section{Introduction}

EM absorbing and shielding materials are utilized to provide protection against EM interference (EMI) as well as EM pollution. The primary strategy to provide EM shielding is to use EM reflective materials, typically metals. EM absorbing materials are needed in anechoic chambers and stealth ships/planes and should have electric and/or magnetic dipoles, which interact with the EM field and attenuate the incident EM waves. Ferrites and metal powders, which produce large electric and magnetic loss, are normally used in this area. ${ }^{1)}$ Recently, electrical insulating polymers, which are EM transparent, were combined with carbonbased fillers to provide EM absorbing and shielding low density composites with outstanding mold ability and processability. ${ }^{2)}$ Furthermore, composites consisting of polymers and carbonbased fillers such as carbon nanotubes (CNTs) or graphene have tailorable complex permittivity and electrical conductivity. ${ }^{3)}$ However, these polymer composites have their intrinsic disadvantages. They cannot be used in structural applications at high temperature and harsh environments, due to their low decomposition temperature. In contrast, nanocomposites consisting of carbon-based fillers dispersed within a EM transparent ceramic matrix (e.g., $\mathrm{Si}_{3} \mathrm{~N}_{4}$ ) may provide great effectiveness in the $\mathrm{X}$ band as well as exceptional stability at high-temperatures and in harsh environments. ${ }^{4)}$

Rather few papers have been reported on graphene/ceramic composites. Among those, most of the studies focused on the effect of the graphene phase on the mechanical properties of the composites. Thus, it was shown that the fracture toughness of

\footnotetext{
† Corresponding author: G. Mera; E-mail: mera@materials. tu-darmstadt.de

* Preface for this article: Dol http://dx.doi.org/10.2109/jcersj2.124.P10-1
}

$\mathrm{Si}_{3} \mathrm{~N}_{4}$ was improved by $\sim 235 \%$, i.e. from 2.8 to $6.6 \mathrm{MPa} \mathrm{m}^{1 / 2}$, at only 1.5 vol\% loading of graphene. ${ }^{5)}$ Also the fracture toughness of alumina was significantly improved (as with 53\%) upon loading with $2 \mathrm{wt} \%$ graphene. ${ }^{6)}$ Regarding the functional properties, enhanced electrical conductivity as well as a rather small percolation threshold $(<3 \mathrm{vol} \%)$ were reported for graphene/ alumina composites. ${ }^{7)}$ However, the dielectric properties of graphene-containing ceramic composites have been rarely studied. ${ }^{8)}$ Similar to graphene/polymer composites, an improved electrical conductivity of graphene-containing ceramic composites may lead to an increase of the dielectric constant and dielectric loss, which makes graphene/ceramic composites suitable in applications which require EM shielding materials.

The main objective of this work was to synthesize graphene/ $\mathrm{Si}_{3} \mathrm{~N}_{4}$ nanocomposite ceramics from a GO-filled preceramic polymer via polymer-derived ceramics route. For this purpose, the synthesis of the preceramic polymer was performed in the presence of highly dispersed GO, yielding a homogeneous $\mathrm{GO} /$ polysilazane composite which was subsequently thermally converted $\left(\mathrm{Ar}, 1100^{\circ} \mathrm{C}\right)$ into graphene/silicon nitride. The prepared nanocomposites were investigated concerning dc and ac conductivity.

\section{Experimental procedure}

\subsection{Materials synthesis}

GO was synthesized via the method reported by Marcano et al. ${ }^{9)}$ Thus, $3.0 \mathrm{~g}$ of graphite flakes were added to a $400 \mathrm{ml}$ mixture of concentrated $\mathrm{H}_{2} \mathrm{SO}_{4}$ and $\mathrm{HNO}_{3}$ (vol. ratio 9:1) and refluxed for $12 \mathrm{~h}$ at $50^{\circ} \mathrm{C}$. The suspension was subsequently diluted upon pouring it onto $600 \mathrm{ml}$ ice while $5 \mathrm{ml} \mathrm{H}_{2} \mathrm{O}_{2}$ was added at the same time. After multiple washing/centrifugation steps, the obtained material was vacuum-dried $\left(10^{-2} \mathrm{mbar}\right)$ at $55^{\circ} \mathrm{C}$ for $4 \mathrm{~h}$. The reduction of GO was carried out through 
Table 1. $\mathrm{rGO} \mathrm{Si}_{3} \mathrm{~N}_{4}$ samples prepared within the present study (the amounts of $\mathrm{SiCl} 4$ and HDMS were constant, while the amount of GO varied)

\begin{tabular}{lccc}
\hline Sample Code & $\begin{array}{c}\text { Amount of } \mathrm{SiCl}_{4} \\
{[\mathrm{~g}]}\end{array}$ & $\begin{array}{c}\text { Amount of HMDS } \\
{[\mathrm{g}]}\end{array}$ & $\begin{array}{c}\text { Amount of GO } \\
{[\mathrm{mg}]}\end{array}$ \\
\hline XF0 & & & 0 \\
XF1 & & & 31 \\
XF2 & 5 & 5.9 & 62 \\
XF5 & & & 155 \\
XF10 & & & 310 \\
\hline
\end{tabular}

thermal pyrolysis in the atmosphere of $\mathrm{Ar}$ and $\mathrm{N}_{2}$ at $1100^{\circ} \mathrm{C}$ with a heating rate of $100 \mathrm{~K} / \mathrm{h}$.

The synthesis of the polysilazane was performed by reacting $\mathrm{SiCl}_{4}$ with HMDS. Thus, $5 \mathrm{~g} \mathrm{SiCl}_{4}$ were added dropwise to a solution of HMDS $(5.9 \mathrm{~g})$ in toluene $(20 \mathrm{ml})$ in the presence of $5 \mathrm{ml}$ of pyridine. The reaction solution was stirred at $0^{\circ} \mathrm{C}$ for $2 \mathrm{~h}$, allowed to reach room temperature and stirred overnight before the solvent was removed in vacuum $\left(10^{-2} \mathrm{mbar}, 40^{\circ} \mathrm{C}\right)$. The obtained solid, colorless powder was thermally treated at two different temperatures $\left(700\right.$ and $1100^{\circ} \mathrm{C}$ ) in $\mathrm{Ar}$ and $\mathrm{N}_{2}$ atmosphere. One additional sample was heated to $1400^{\circ} \mathrm{C}$ in Ar atmosphere. The obtained ceramic samples are referred to as XF0_700Ar, XF0_1100Ar, XF0_700N2, XF0_1100N2 and XF0_1400Ar, respectively. Furthermore, a $\mathrm{Si}_{3} \mathrm{~N}_{4}$-based monolithic sample (referred to as hot-pressed XF0) was prepared via hot-pressing of XF0_1100N2 (45 MPa, $1600^{\circ} \mathrm{C}$, N2 atmosphere).

The synthesis of the polysilazane was additionally performed in the presence of different amounts of GO. Thus, in this case, $\mathrm{SiCl}_{4}$ was added dropwise to HMDS solutions containing the dispersed GO phase. The GO/polysilazane composites were subsequently processed in a similar manner as the graphene-free materials. The obtained graphene $/ \mathrm{Si}_{3} \mathrm{~N}_{4}$ samples prepared within this study are listed in Table 1.

\subsection{Materials characterization}

Fourier transform infrared (FTIR) spectra were recorded on a Varian 670-IR spectrometer. X-ray diffraction (XRD) patterns were collected on a STOE STADI P transmission diffractometer with Mo K $\alpha$ radiation $(17.5 \mathrm{keV}, 0.709 \AA)$. The XRD measurements on the monolithic samples were taken on a Bruker D8 Powder diffractometer with $\mathrm{Cu} \mathrm{K} \alpha$ radiation $(8.05 \mathrm{keV}, 1.57 \AA)$. The data were collected over an incident angle $(2 \theta)$ range of 5 to $45^{\circ}$ by using a step size of $0.2^{\circ}$ and $20 \mathrm{~s}$ count time per measurement. Raman spectroscopy was performed with a LabRAM HR800 machine (Horiba Jobin Yvon) using $\mathrm{He} / \mathrm{Ne}(633 \mathrm{~nm})$ and Ar laser excitation $(514 \mathrm{~nm})$. Thermogravimetric analysis (TGA), differential thermal analysis (DTA), and mass spectrometric analysis (MS) were carried out with a Netzsch STA 449 C Jupiter TA device. The elemental analysis $(\mathrm{C}, \mathrm{N}, \mathrm{O})$ of the samples was performed on LECO C-200 and LECO TC-436 devices. The characterization of microstructure was performed with using a Philips XL30 FEG high-resolution scanning electron microscope (SEM) equipped with energy dispersive X-ray spectroscope and a transmission electron microscope (TEM JEM-2100F, JEOL, Co. Ltd., Japan) operated at $200 \mathrm{kV}$. For the TEM observation, the samples were grinded into fine powders and dispersed in ethanol (>99.5\%, Junsei-Chemical Co. Ltd., Japan) using an ultrasonic bath. A small amount of the suspension was caught from the top of solution and dropped on a thin carbon film supported by $\mathrm{Cu}$ grid. The residual open porosity as well as the density of the monolithic samples prepared upon hot-pressing were assessed using the water immersion method. The relative permittivity and electrical conductivity of the monolithic samples were measured by means of impedance spectroscopy with an Alpha-A13 Analyzer in the frequency range of 1 to $10^{7} \mathrm{~Hz}$.

\section{Results and discussion}

In order to understand the properties of resulting $\mathrm{rGO}-\mathrm{Si}_{3} \mathrm{~N}_{4}$ nanocomposite, the components $\mathrm{rGO}$ and $\mathrm{Si}_{3} \mathrm{~N}_{4}$ resulted from the thermal decomposition of $\mathrm{GO}$ and the polysilazane respectively, were analyzed individually. A special attention for accorded to the synthesis of silicon nitride from a highly cross-linked polysilazane produced via a reaction of $\mathrm{SiCl}_{4}$ with HMDS.

\subsection{Preparation and characterization of rGO}

FTIR spectroscopy was used to assess the as-prepared GO [Fig. 1(a)]. Absorption bands at $3420(\mathrm{OH}), 1720(\mathrm{C}=\mathrm{O}), 1220$ $(\mathrm{C}-\mathrm{O})$ and $1100 \mathrm{~cm}^{-1}(\mathrm{C}-\mathrm{O}-\mathrm{C})$ indicate the successful preparation of GO. ${ }^{10)}$

Figure 1(b) shows the XRD pattern of the prepared of GO. The interlayer spacing of the prepared GO was found to be $0.920 \mathrm{~nm}$, which is significantly higher than that of graphite $(0.335 \mathrm{~nm})^{11)}$ and reveals that the GO prepared in this work was highly oxidized. The thickness of the GO crystallites was estimated by the Scherrer's equation to be ca. $11.6 \mathrm{~nm}$. Thus, it is estimated that the prepared GO crystallites consist in average of ca. 12-13 graphene sheets.

Thermogravimetric analysis of GO coupled with in situ MS was carried out under argon up to $1400^{\circ} \mathrm{C}$ (Fig. 2). GO shows a slight mass loss from room temperature to $100^{\circ} \mathrm{C}$, followed by a remarkable mass loss up to $250^{\circ} \mathrm{C}$. At higher temperature, the mass of GO further decreases. The mass loss up to $100^{\circ} \mathrm{C}$ is due to the elimination of inter-lamellar water, whereas the major mass loss up to $250^{\circ} \mathrm{C}$ is assigned to the release of oxygen functionalities in GO. Thus, the mass loss in this temperature range is accompanied by the release of gaseous $\mathrm{CO}, \mathrm{CO}_{2}$ and $\mathrm{H}_{2} \mathrm{O} .{ }^{12)}$ At higher temperatures a steady mass loss is recorded, which indicates a further reduction of GO. Thus, the release of amount of $\mathrm{CO}_{2}$ and $\mathrm{CO}$ has been detected up to 700 and $900^{\circ} \mathrm{C}$, respectively. This has been attributed to the sublimation or removing of the damaged/oxidized graphitic regions. ${ }^{13), 14)}$

Thermally reduced graphene ( $\mathrm{rGO})$, which was obtained via thermal treatment of $\mathrm{GO}$ at $1100^{\circ} \mathrm{C}$ (in $\mathrm{Ar} / \mathrm{N}_{2}$ atmosphere), was studied by FTIR and Raman spectroscopy (Fig. 3). The FTIR spectrum of rGO [Fig. 3(a)] indicates the almost complete removal of hydroxyl as well as carboxyl groups (elimination of absorption bands at 1740,1230 and $3200-3300 \mathrm{~cm}^{-1}$ ); whereas some residual epoxy groups are left. Moreover, the absorption band at $1630 \mathrm{~cm}^{-1}(\mathrm{C}=\mathrm{C})$ also vanished in the FTIR spectra of rGO. ${ }^{15), 16)}$

The GO and rGO samples were also investigated by Raman spectroscopy, which is a very sensitive technique in order to evaluate the nano/microstructure of carbon-based materials and consequently provide valuable information about their ordering, hybridization, defect state etc. The first order Raman spectrum of $\mathrm{sp}^{2}$ carbon exhibits a band of $E_{2 \mathrm{~g}}$ symmetry, which relates to bond stretching of $\mathrm{sp}^{2}$ carbon pairs contained in rings or chains. This band is called G band and appears at around 1575-1595 $\mathrm{cm}^{-1}$. Disordered or nanostructured carbon-based materials, which might contain also some amount of $\mathrm{sp}^{3}$ hybridization, exhibit additional bands in their first order Raman spectrum, such as a band of $A_{1 g}$ symmetry, which relates to breathing modes of $\mathrm{sp}^{2}$ carbon atoms within rings (so-called $\mathrm{D}$ band; its position depends on the laser wavelength; ca. $1350 \mathrm{~cm}^{-1}$ at $514.5 \mathrm{~nm}$ ), a 


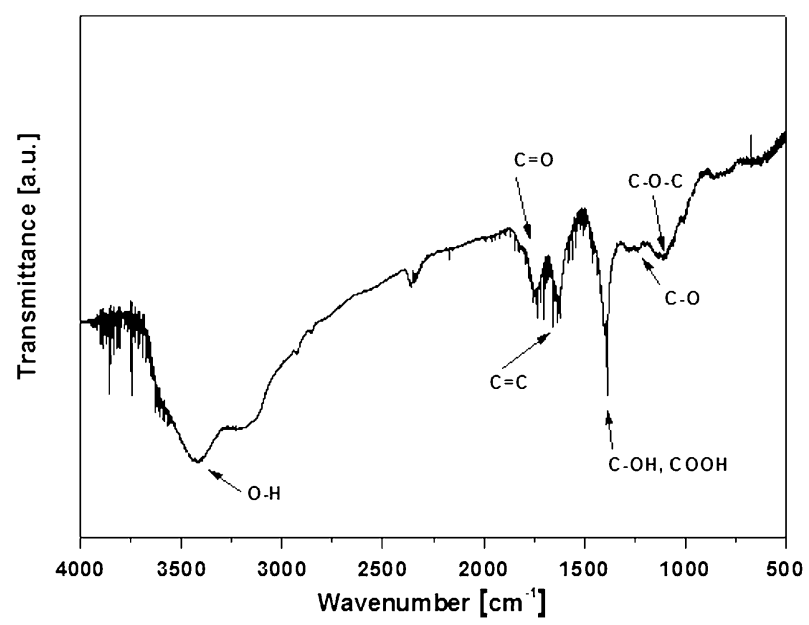

(a)

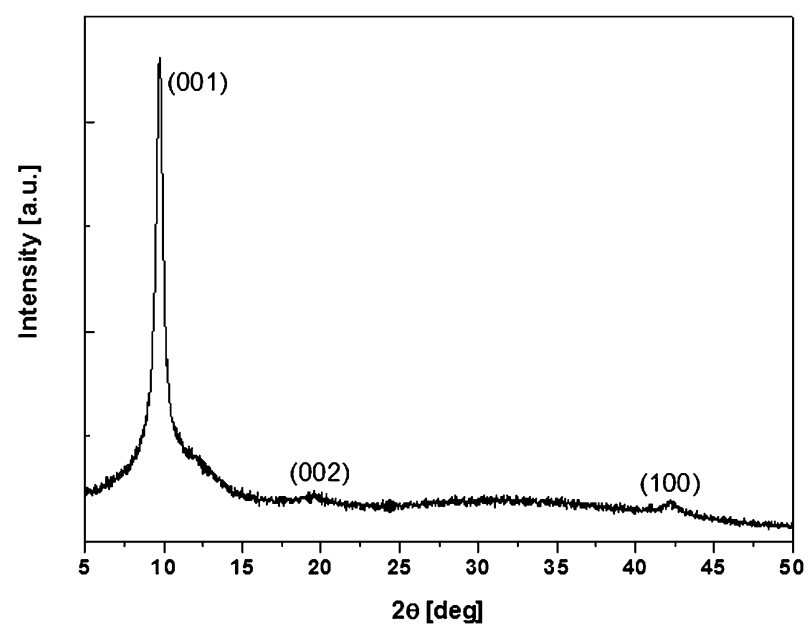

(b)

Fig. 1. FTIR spectrum (a) and XRD pattern (b) of the as-prepared GO.

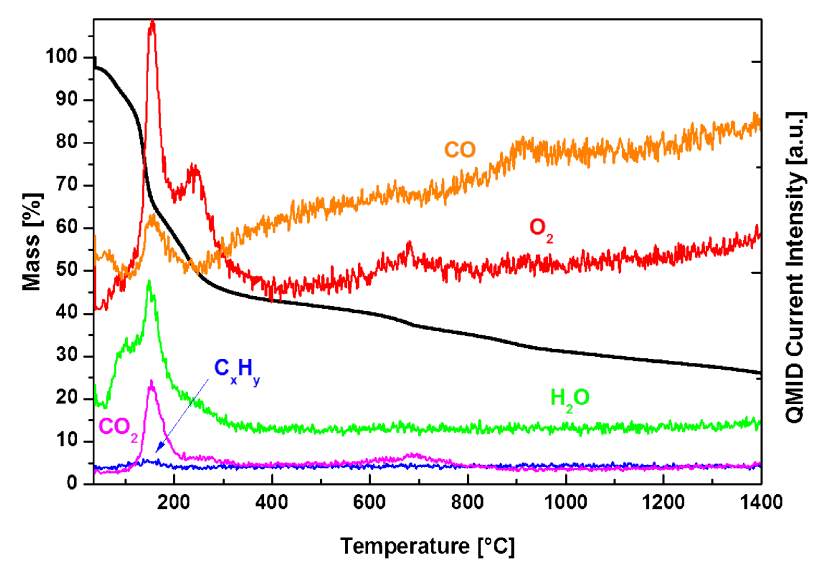

Fig. 2. TG (black line) and QMID (quasi multiple ion detection, colored curves, as for different gaseous species) ion current curves during the heat treatment of GO in argon.

band related to $\mathrm{C}-\mathrm{C} \mathrm{sp} \mathrm{sp}^{3}$ vibrations (ca. $1150-1200 \mathrm{~cm}^{-1} ; \mathrm{A}_{1 \mathrm{~g}}$ symmetry, $\mathrm{T}$ band), a $\mathrm{D}^{\prime \prime}$ band (ca. $1500 \mathrm{~cm}^{-1}$, related to amorphous carbon), as well as a $\mathrm{D}^{\prime}$ band ( $\mathrm{E}_{2 \mathrm{~g}}$ symmetry, ca. 1620 $\mathrm{cm}^{-1}$, disordered graphitic lattice related to surface graphene layers $)^{17), 18}$. Figure $3(\mathrm{~b})$ shows the Raman spectra of GO and two rGO samples (as-prepared upon thermal treatment of GO

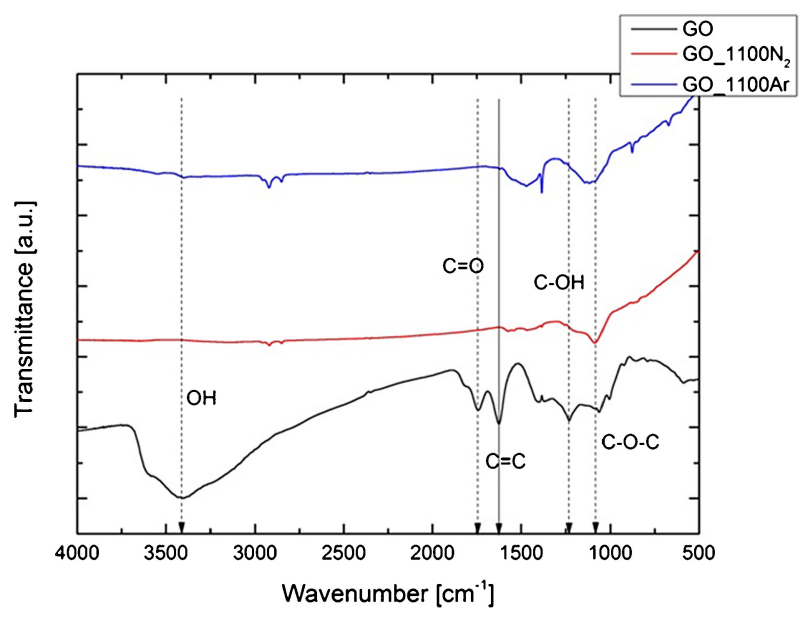

(a)

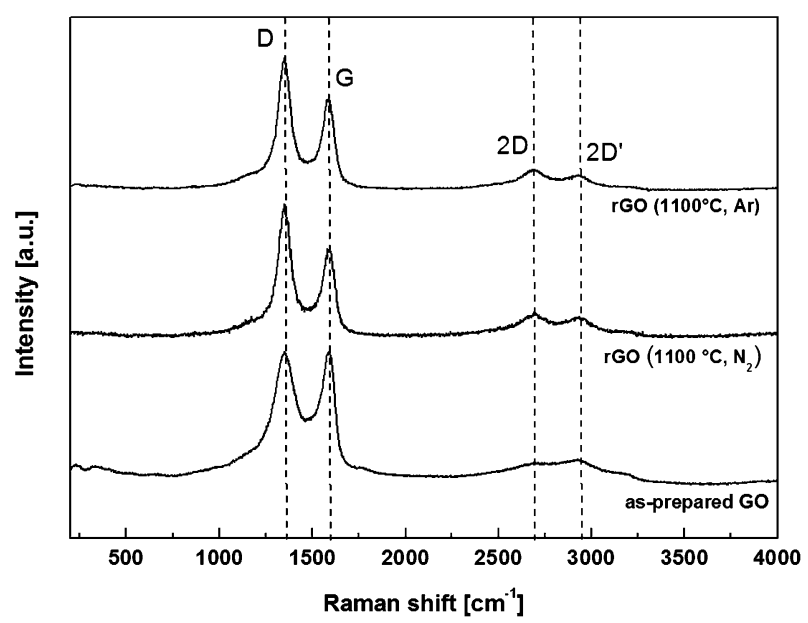

(b)

Fig. 3. FTIR (a) and Raman (b) spectra of GO and $\mathrm{rGO}$ obtained upon heat treatment in nitrogen (GO_1100N2) and argon (GO_1100Ar) atmosphere.

Table 2. Raman graphitization indices $\left(\mathrm{L}_{\mathrm{a}}, \mathrm{L}_{\mathrm{eq}}\right)$ for the as-prepared GO and $\mathrm{rGO}$

\begin{tabular}{lcccc}
\hline & $\mathrm{I}_{\mathrm{D}} / \mathrm{I}_{\mathrm{G}}$ & $\mathrm{A}_{\mathrm{D}} / \mathrm{A}_{\mathrm{G}}$ & $\mathrm{L}_{\mathrm{a}}[\mathrm{nm}]$ & $\mathrm{L}_{\mathrm{eq}}[\mathrm{nm}]$ \\
\hline $\mathrm{GO}$ & 1.59 & 2.57 & 1.57 & 2.04 \\
rGO_1100N 2 & 1.87 & 2.73 & 1.50 & 2.34 \\
rGO_1100Ar & 1.90 & 2.74 & 1.59 & 2.27 \\
\hline
\end{tabular}

in $\mathrm{N}_{2} / \mathrm{Ar}$ atmosphere), which exhibit two main bands, at 1580 and $1360 \mathrm{~cm}^{-1}$. An additional band at ca. $2700 \mathrm{~cm}^{-1}$, which is referred to as 2D band (second order band), can also be observed in the Raman spectra in Fig. 3(b).

Table 2 summarizes some Raman graphitization indices such as the intensity ratio of the $\mathrm{D}$ and $\mathrm{G}$ modes $\left(\mathrm{I}_{\mathrm{D}} / \mathrm{I}_{\mathrm{G}}, \mathrm{A}_{\mathrm{D}} / \mathrm{A}_{\mathrm{G}}\right)$, the lateral cluster size $\mathrm{L}_{\mathrm{a}}\left[L_{a}=4.4\left(A_{D} / A_{G}\right)^{-1} \mathrm{~nm}\right]^{19), 20)}$ as well as the parameter $\mathrm{L}_{\mathrm{eq}}$ which describes the average continuous graphene length including tortuosity and is defined cf. $L_{e q}=8.8\left(A_{2 D} / A_{G}\right)^{-1}$ $\mathrm{nm}^{21)}$

As shown in Fig. 3(b), the thermal reduction of GO induces an increase of the $\mathrm{I}_{\mathrm{D}} / \mathrm{I}_{\mathrm{G}}$ ratio from 1.59 (in the as-prepared GO) to 1.87 and 1.90 in $\mathrm{rGO}$ obtained in $\mathrm{N}_{2}$ and $\mathrm{Ar}$ atmosphere, respectively (see Table 3 ). Interestingly, the values of $\mathrm{L}_{\mathrm{eq}}$ are only slightly larger than those of $\mathrm{L}_{\mathrm{a}}$, indicating that probably the 


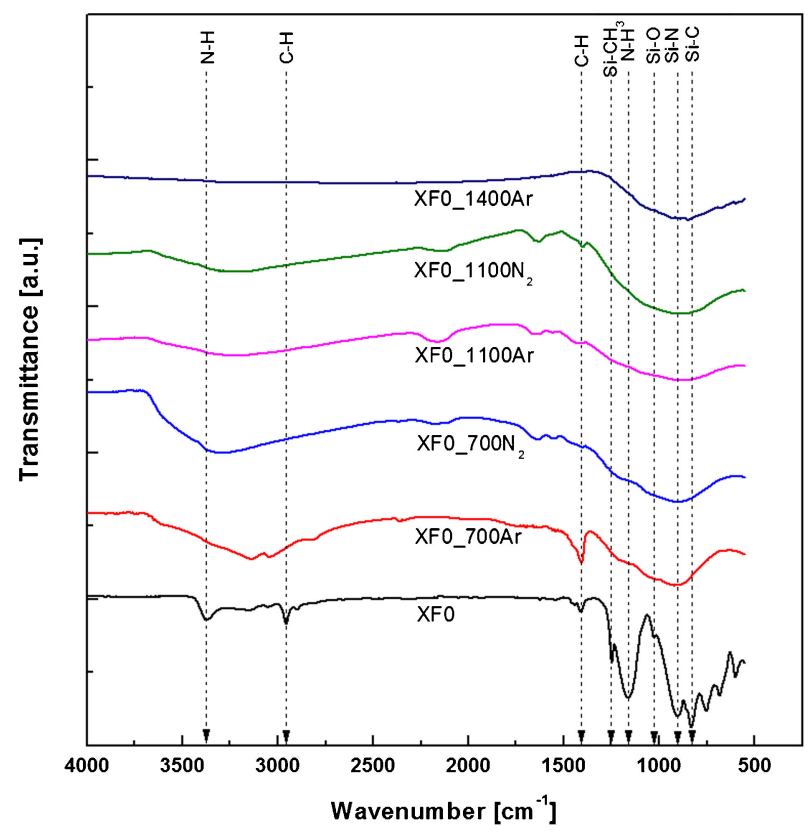

Fig. 4. FTIR spectrum of XF0 and of the resulting silicon nitride ceramics synthesized upon pyrolysis at different temperatures in $\mathrm{Ar}$ and $\mathrm{N}_{2}$ atmospheres.

size of the rGO sheets is rather small. However, the equations used for the estimation of $\mathrm{L}_{\mathrm{a}}$ and $\mathrm{L}_{\mathrm{eq}}$ have large uncertainty for $\mathrm{L}_{\mathrm{a}} / \mathrm{L}_{\mathrm{eq}}<5 \mathrm{~nm}^{22)}$ and consequently the values of $\mathrm{L}_{\mathrm{a}}$ and $\mathrm{L}_{\mathrm{eq}}$ must be treated carefully, as they usually are strongly underestimated (please see the discussion on the TEM data below).

\subsection{Preparation of silicon nitride}

Hexamethyldisilazane (HMDS) was reacted with tetrachlorosilane in the presence of catalytical amounts of pyridine. The novel preceramic polymer was characterized by FTIR spectroscopy (see XF0 in Fig. 4). The strong absorption peak at 3380 $\mathrm{cm}^{-1}$ is assigned to the $\mathrm{N}-\mathrm{H}$ stretch vibrations. The absence of a double peak in the $\mathrm{N}-\mathrm{H}$ absorptions area indicates that there are no $-\mathrm{NH}_{2}$ groups present in the precursor. The absorption bands at $2900-2955 \mathrm{~cm}^{-1}$ as well as $1409 \mathrm{~cm}^{-1}$ are attributed to $\mathrm{C}-\mathrm{H}$ bonding. $\mathrm{Si}-\mathrm{CH}_{3}$ stretch vibrations are also confirmed by the absorption at $1250 \mathrm{~cm}^{-1}$. Additionally, very strong bands related to $\mathrm{Si}-\mathrm{N}-\mathrm{H}, \mathrm{Si}-\mathrm{N}-\mathrm{Si}$ as well as $\mathrm{Si}-\mathrm{C}$ were identified at 1160, 907 and $823 \mathrm{~cm}^{-1}$, respectively. Additionally, an absorption band at $1026 \mathrm{~cm}^{-1}$ was analyzed and assigned to $\mathrm{Si}-\mathrm{O}-\mathrm{Si}$ groups and is related to slight contamination of the precursor with oxygen during the synthesis procedure.

The polymer-to-ceramic transformation of the prepared polysilazane was assessed by TGA/DTA (Fig. 5). The ceramic yield of the preceramic polymer was $47 \%$ and the ceramization process presents three main decomposition steps. The first step (mass loss of ca. $24 \mathrm{wt} \%$ ) occurs at ca. $200^{\circ} \mathrm{C}$ and is predominantly caused by the evaporation of low weight molecules (oligomers); their presence can be explained by the fact that the synthesized polysilazane is probably not highly polymerized and additionally does not exhibit cross-linkable substituents such as $\mathrm{Si}-\mathrm{H}$ or vinyl groups. The second step (mass loss ca. $24 \mathrm{wt} \%$ ) occurs between 200 and $700^{\circ} \mathrm{C}$ and mainly relies on transamination processes and the release of hydrocarbons (i.e., $\mathrm{CH}_{4}$ ), as detected by in situ MS (not shown here). At higher temperatures, a third mass loss step was determined and it relates to the release of ammonia and methane.

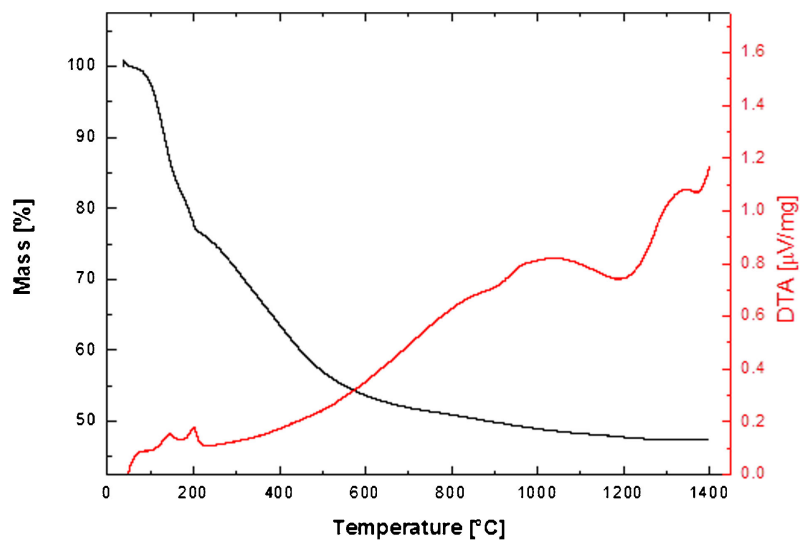

Fig. 5. TG (black line) and DTA (red line) curves during the thermal treatment of XF0 in argon atmosphere.

The XRD patterns of the XF0-based samples prepared upon pyrolysis in argon atmosphere at 1100,1400 and $1600^{\circ} \mathrm{C}$, are illustrated in Fig. 6. XF0_1100 was found to be X-ray amorphous; whereas the samples prepared at 1400 and $1700^{\circ} \mathrm{C}$ exhibited the presence of $\alpha-\mathrm{Si}_{3} \mathrm{~N}_{4}$ as crystalline phase.

\subsection{Synthesis and characterization of $\mathrm{rGO} / \mathrm{Si}_{3} \mathrm{~N}_{4}$ nanocomposites}

The rGO-containing $\mathrm{Si}_{3} \mathrm{~N}_{4}$ nanocomposites were prepared from precursors synthesized upon mixing GO with HMDS and $\mathrm{SiCl}_{4}$ in the presence of pyridine. FTIR spectroscopy results (see Supporting Information) revealed no significant differences between the GO-containing precursors and the neat polymer. Whereas the FTIR spectra of the $\mathrm{rGO} / \mathrm{Si}_{3} \mathrm{~N}_{4}$ samples obtained upon pyrolysis show the presence of an absorption band assigned to $\mathrm{Si}-\mathrm{O}-\mathrm{Si}$ units, which probably relate to the interface bonding between the rGO phase and the silicon nitride matrix.

The synthesized $\mathrm{rGO} / \mathrm{SiN}_{x}$ nanocomposites were characterized by transmission electron microscopy (TEM). Figure 7 displays TEM micrographs of XF10 prepared upon pyrolysis at $1100^{\circ} \mathrm{C}$.

The ceramic nanocomposite seems to be rather amorphous. The TEM micrographs indicate the presence of randomly oriented, well exfoliated and distributed $\mathrm{rGO}$, which are uniformly embedded within the ceramic matrix. Additionally, some amount of mesopores was also identified within the microstructure of the nanocomposites. According to the high-magnification TEM micrographs Fig. 7(b), the rGO nanoparticles consist of 8-10 graphene layers. This result agrees well with that obtained from the XRD data of the as-prepared GO, thus indicating that the pyrolysis process did not significantly affect its stacking number. The interlayer distance in the rGO particles was determined to be $0.37 \mathrm{~nm}$, which is larger than the interlayer distance in graphite (i.e., $0.335 \mathrm{~nm}$ ) but significantly shorter than that found in the asprepared GO $(0.855 \mathrm{~nm})$. Moreover, the rGO precipitations were found to be highly wrinkled (see Fig. 7) and have aspect ratios in the range of 20 to 40 .

The chemical composition of the $\mathrm{rGO} / \mathrm{SiN}_{x}$ samples prepared upon pyrolysis at $1100^{\circ} \mathrm{C}$ in $\mathrm{N}_{2}$ atmosphere is shown in Table 3 . The samples exhibit the presence of relatively large amounts of oxygen, which relies on the use of GO for the preparation of the nanocomposites. Moreover, the carbon content in the GO-free silicon nitride was negligible; whereas the $\mathrm{C}$ content in the $\mathrm{rGO} /$ $\mathrm{SiN}_{x}$ nanocomposites increases as the amount of GO is increased, indicating GO as being the source for the carbon content in the nanocomposites. 
Table 3. Chemical composition of the as-prepared $\mathrm{rGO}-\mathrm{Si}_{3} \mathrm{~N}_{4}$ samples $\left(1100^{\circ} \mathrm{C}, \mathrm{N}_{2}\right.$ atmosphere)

\begin{tabular}{|c|c|c|c|c|c|c|c|c|c|}
\hline \multirow{2}{*}{ Name } & \multirow{2}{*}{$\begin{array}{c}\mathrm{Si} \\
{[\mathrm{wt} \%]}\end{array}$} & \multirow{2}{*}{$\begin{array}{c}\mathrm{C} \\
{[\mathrm{wt} \%]}\end{array}$} & \multirow{2}{*}{$\begin{array}{c}\mathrm{N} \\
{[\mathrm{wt} \%]}\end{array}$} & \multirow{2}{*}{$\begin{array}{c}\mathrm{O} \\
{[\mathrm{wt} \%]}\end{array}$} & \multirow{2}{*}{ Empirical Formula } & \multicolumn{4}{|c|}{ Phase Composition [vol\%] } \\
\hline & & & & & & $\mathrm{Si}_{3} \mathrm{~N}_{4}$ & $\mathrm{SiO}_{2}$ & $\mathrm{Si}$ & $\mathrm{rGO}$ \\
\hline XF0 & 59.27 & 0.10 & 24.67 & 15.96 & $\mathrm{Si}_{1} \mathrm{~N}_{0.83} \mathrm{O}_{0.47} \mathrm{C}_{0.004}$ & 50.91 & 42.33 & 6.76 & 0 \\
\hline $\mathrm{XF} 1$ & 65.85 & 1.06 & 27.62 & 11.47 & $\mathrm{Si}_{1} \mathrm{~N}_{0.93} \mathrm{O}_{0.34} \mathrm{C}_{0.04}$ & 60.38 & 27.85 & 10.20 & 1.56 \\
\hline $\mathrm{XF} 2$ & 63.12 & 1.72 & 26.04 & 9.12 & $\mathrm{Si}_{1} \mathrm{~N}_{0.83} \mathrm{O}_{0.25} \mathrm{C}_{0.06}$ & 57.84 & 20.58 & 19.13 & 2.45 \\
\hline XF5 & 58.62 & 2.53 & 18.56 & 20.29 & $\mathrm{Si}_{1} \mathrm{~N}_{0.64} \mathrm{O}_{0.61} \mathrm{C}_{0.10}$ & 37.84 & 44.22 & 14.48 & 3.46 \\
\hline $\mathrm{XF} 10$ & 54.38 & 5.24 & 23.89 & 16.49 & $\mathrm{Si}_{1} \mathrm{~N}_{0.88} \mathrm{O}_{0.53} \mathrm{C}_{0.22}$ & 49.81 & 37.57 & 5.14 & 7.47 \\
\hline
\end{tabular}

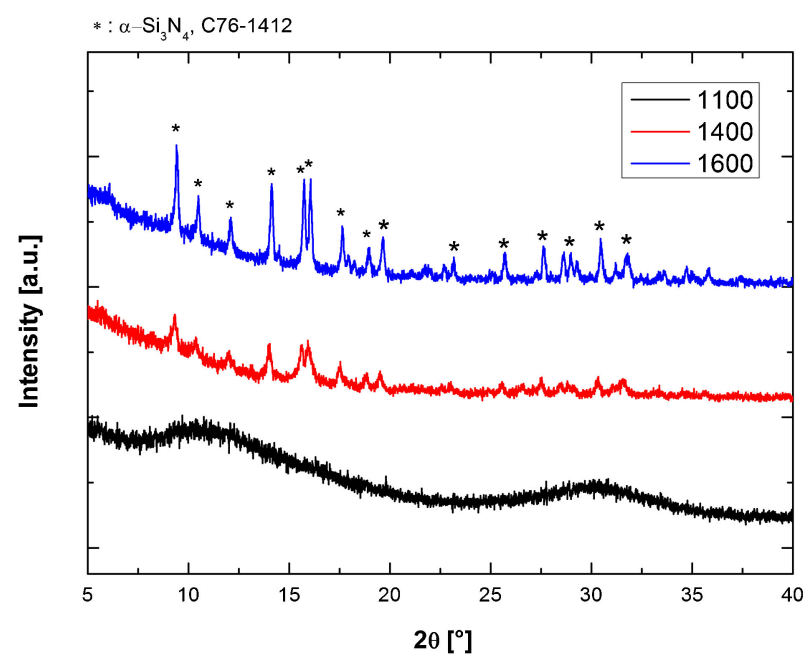

Fig. 6. XRD patterns of XF0 prepared upon pyrolysis at 1100,1400 and $1600^{\circ} \mathrm{C}$ in argon atmosphere.

From the chemical composition of the prepared nanocomposites, the volume fraction of $\mathrm{rGO}$ was estimated. As shown before, the interlayer distance in the rGO particles was $0.37 \mathrm{~nm}$. Considering the density of rGO being inversely proportional to the interlayer distance, the density of rGO in the as-prepared $\mathrm{rGO} / \mathrm{SiN}_{x}$ nanocomposites was estimated to be $1870 \mathrm{~kg} / \mathrm{m}^{3}$ [cf. $\left.\rho_{r G O}=\left(\rho_{\text {Graphite }} \cdot d_{\text {Graphite }} / d_{r G O}\right)\right]$. The volume fractions of rGO in the prepared nanocomposites were evaluated upon considering the matrix material consisting of $\mathrm{Si}_{3} \mathrm{~N}_{4}$ (density $3200 \mathrm{~kg} / \mathrm{m}^{3}$ ), $\mathrm{SiO}_{2}\left(2200 \mathrm{~kg} / \mathrm{m}^{3}\right)$ and excess silicon $\left(2300 \mathrm{~kg} / \mathrm{m}^{3}\right)$ and are listed in Table 3.

The $\mathrm{rGO} / \mathrm{Si}_{3} \mathrm{~N}_{4}$ samples prepared upon pyrolysis at $1100^{\circ} \mathrm{C}$ were hot-pressed at $1600^{\circ} \mathrm{C}$ in nitrogen atmosphere to prepare monolithic $\mathrm{rGO} / \mathrm{Si}_{3} \mathrm{~N}_{4}$ nanocomposites. The Raman spectra are shown in Fig. 8. The sample XF0 shows the presence of absorption bands in the range of 400 to $1000 \mathrm{~cm}^{-1}$ [Fig. 8(a)] which were assigned to $\alpha-\mathrm{Si}_{3} \mathrm{~N}_{4}{ }^{23)}$ In the Raman spectra of the rGOcontaining nanocomposites, i.e. XF5 and XF10, the typical absorption bands of carbon (D, G and 2D bands) can be also identified and were assigned to the rGO phase.

Figure 9 shows the XRD patterns of the hot-pressed monoliths. All samples show the presence of $\alpha-\mathrm{Si}_{3} \mathrm{~N}_{4}$. In the XRD patterns of rGO-containing samples, two additional reflections were observed at 15.2 and $16.84^{\circ}$, whose assignment was not possible yet.

Note that no crystalline $\mathrm{SiC}$ was present in the hot-pressed $\mathrm{rGO} / \mathrm{Si}_{3} \mathrm{~N}_{4}$ samples, indicating that the reaction of the $\mathrm{rGO}$ phase with $\mathrm{Si}_{3} \mathrm{~N}_{4}$ to form $\beta$-SiC and gaseous $\mathrm{N}_{2}$ is suppressed. Additionally, the crystallinity of the samples XF0, XF1 and XF2 was found to be significantly higher as that in XF5 and XF10, indicating that the rGO phase suppresses the crystallization of $\mathrm{Si}_{3} \mathrm{~N}_{4}$ ceramics. This is in agreement to observations made in
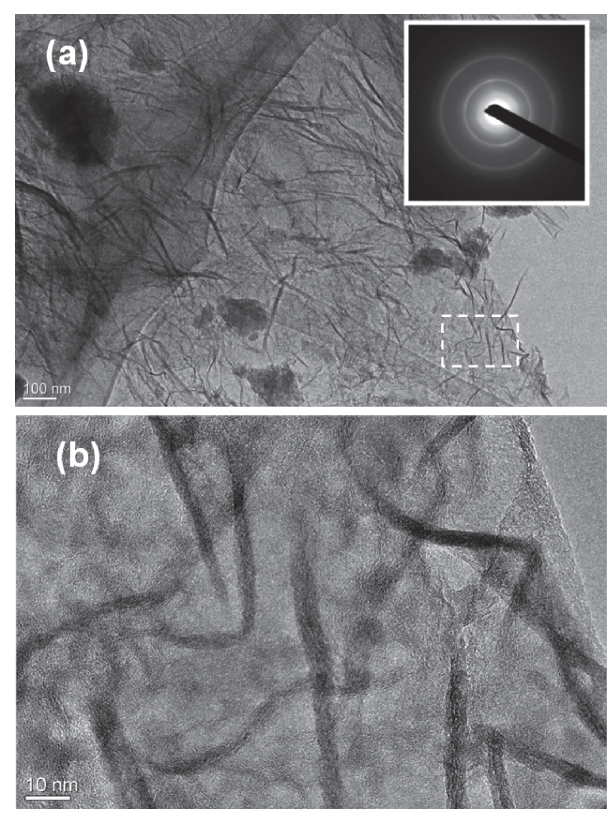

Fig. 7. Typical TEM micrographs of as-prepared XF10. The marked region in (a) is shown magnified in (b).

polymer-derived ceramics (i.e., $\mathrm{SiCN}$ materials), which were also shown to have an improved crystallization resistance at hightemperatures as the fraction of the segregated carbon phase increases. ${ }^{24), 25)}$

The TEM image of hot-pressed XF10 is shown in Fig. 10. The presence of $\alpha-\mathrm{Si}_{3} \mathrm{~N}_{4}$ nanocrystals with an average size of $10 \mathrm{~nm}$ can be clearly seen and thus supports the results obtained via XRD. Moreover, the tortuous rGO phase which in some regions consists of just 2 graphene layers can also be observed, indicating the successful preparation of a $\mathrm{Si}_{3} \mathrm{~N}_{4}$ nano composites containing a well dispersed graphene-like phase.

The skeletal density and the open porosity values for the prepared hot-pressed samples are summarized in Table 4, indicating rather high porosity in all monolithic samples. This is obviously related to the very low self-diffusion coefficients in the silicon nitride matrix. Despite the obtained samples were not dense, they were used for the assessment of their dielectric properties (the effect of porosity on the electrical conductivity and dielectric constant was taken into account though).

The dc electrical conductivity of the hot-pressed samples was assessed. The electrical conductivity $\sigma$ has been defined as the inverse of the electrical resistivity $(\rho)$, i.e. $\sigma=(1 / \rho)$, whereas $\rho$ relates to the resistance $\mathrm{R}$ and the sample dimensions cf. $\rho=R(A / l)$. The values of the electrical conductivity of the hotpressed samples are listed in Table $\mathbf{5}$.

The rGO-free $\mathrm{Si}_{3} \mathrm{~N}_{4}$ monolith (i.e., XF0) has an electrical conductivity of $1.09 \times 10^{-11} \mathrm{~S} / \mathrm{m}$, which is similar to reported 

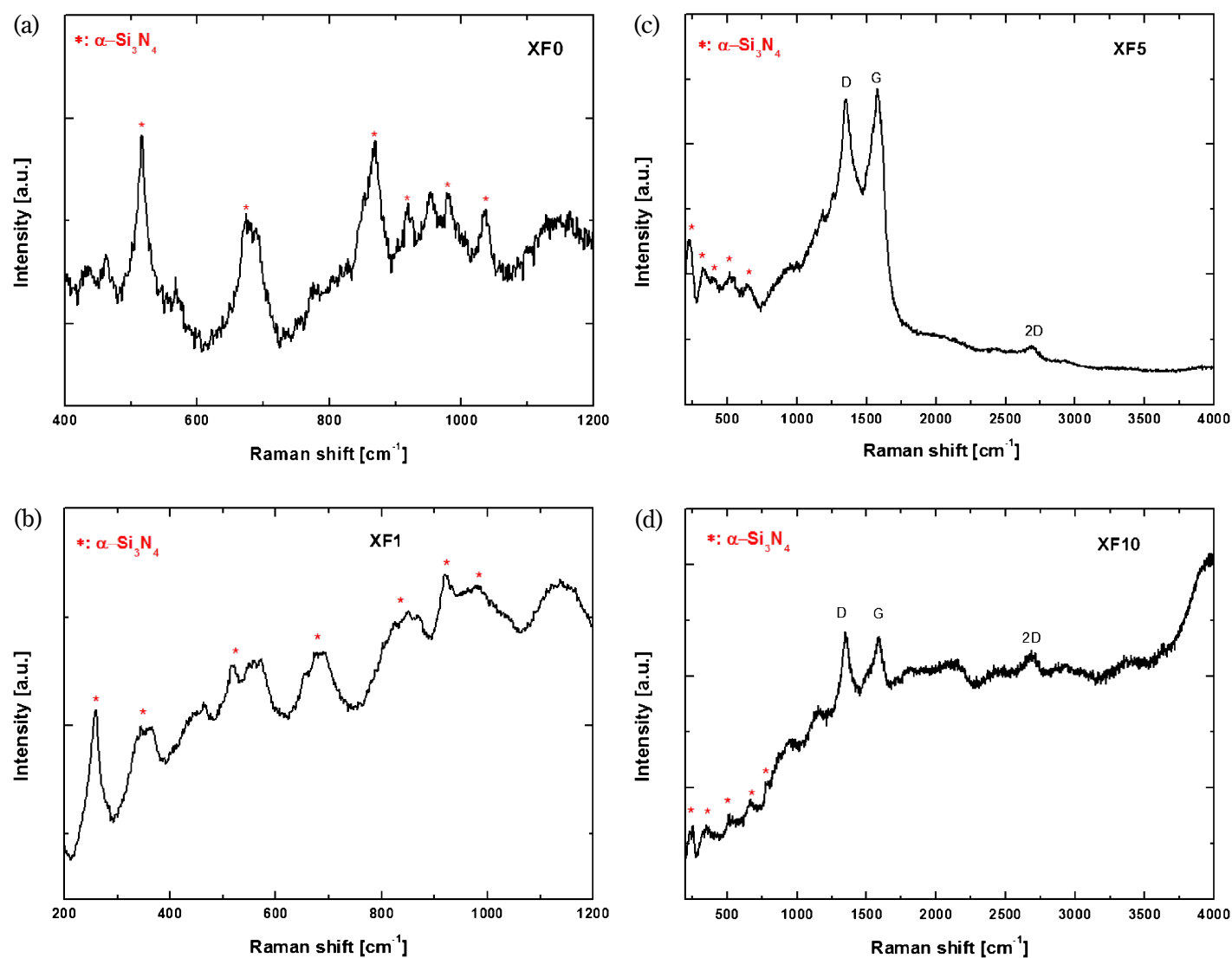

Fig. 8. Raman spectra of XF0 (a), XF1 (b), XF5 (c) and XF10 (d) prepared upon hot-pressing at $1600^{\circ} \mathrm{C}$ in $\mathrm{N}_{2}$ atmosphere.

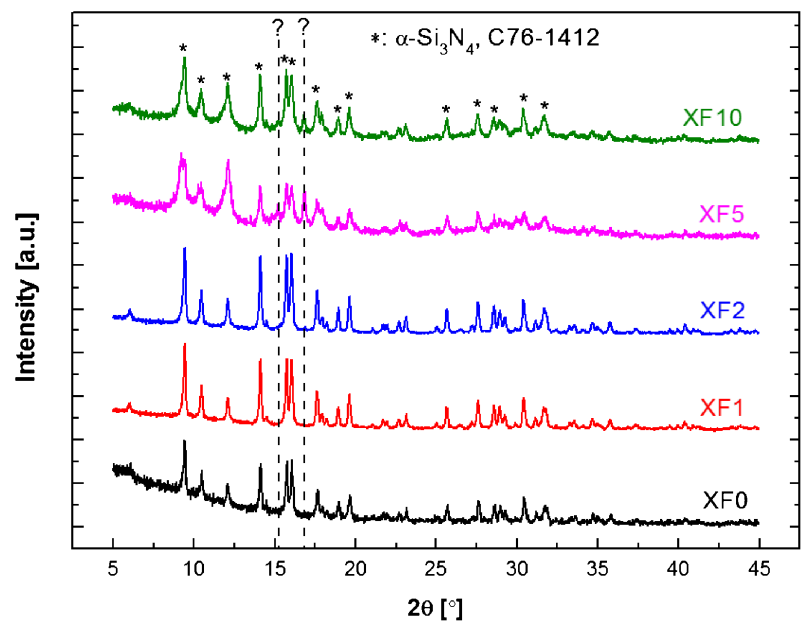

Fig. 9. XRD patterns of hot-pressed XF0 XF1, XF2, XF5 and XF10.

values for $\mathrm{Si}_{3} \mathrm{~N}_{4}$-based ceramics. ${ }^{26)}$ Upon increasing the volume fraction of $\mathrm{rGO}$, the electrical conductivity increases significantly. For instance, the electrical conductivity of XF5 (3.46 vol\% rGO) was found to be $1.9 \times 10^{-5} \mathrm{~S} / \mathrm{m}$ and thus six orders of magnitude higher than that of the $\mathrm{rGO}-$ free $\mathrm{Si}_{3} \mathrm{~N}_{4}$. Whereas XF10 exhibited an electrical conductivity of $2.64 \times 10^{-1} \mathrm{~S} / \mathrm{m}$ (Fig. 11).

Despite the fact that the rGO phase is well distributed within the $\mathrm{Si}_{3} \mathrm{~N}_{4}$ matrix material, the percolation threshold in the prepared $\mathrm{rGO} / \mathrm{Si}_{3} \mathrm{~N}_{4}$ nanocomposites is estimated to be in the range of 2 to $7 \mathrm{vol} \%$, which is relative large in comparison to those of other reported graphene-based composites material. ${ }^{27}$ This probably might rely on the small aspect ratio of the rGO phase.

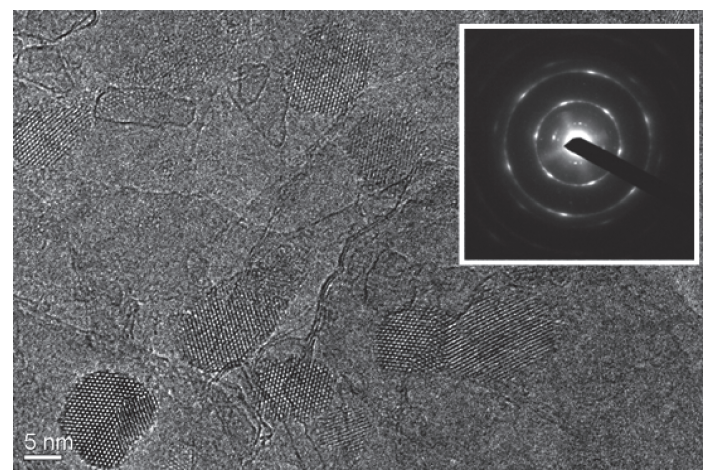

Fig. 10. HR-TEM micrograph of hot-pressed XF10, showing the presence of $\alpha-\mathrm{Si}_{3} \mathrm{~N}_{4}$ nanocrystallites and well-dispersed few-layer rGO.

Table 4. Porosity and skeletal density of hot-pressed $\mathrm{Si}_{3} \mathrm{~N}_{4}$ and rGO/ $\mathrm{Si}_{3} \mathrm{~N}_{4}$ samples

\begin{tabular}{lcc}
\hline Sample & Porosity $[\%]$ & Skeletal Density $\left[\mathrm{kg} / \mathrm{m}^{3}\right]$ \\
\hline XF0 & 32.9 & 1780 \\
XF1 & 42.4 & 1540 \\
XF2 & 25.9 & 1850 \\
XF5 & 38.6 & 1690 \\
XF10 & 44.6 & 1550 \\
\hline
\end{tabular}

Figure 12 shows the relative complex permittivity $\varepsilon$ (both the real and the imaginary part, cf. $\left.\varepsilon=\varepsilon^{\prime}+\mathrm{i} \varepsilon^{\prime \prime}\right)$ and the dielectric loss $\tan \delta$ for the hot-pressed $\mathrm{Si}_{3} \mathrm{~N}_{4}$ and $\mathrm{rGO} / \mathrm{Si}_{3} \mathrm{~N}_{4}$ samples as functions of the frequency (the frequency range was from 1 and 
Table 5. Electrical conductivity of the hot-pressed $\mathrm{rGO} / \mathrm{Si}_{3} \mathrm{~N}_{4}$ samples

\begin{tabular}{lcc}
\hline Sample & Volume fraction $[\%]$ & Electrical conductivity $[\mathrm{S} / \mathrm{m}]$ \\
\hline XF0 & 0 & $1.09 \mathrm{E}-11$ \\
XF1 & 1.56 & $1.54 \mathrm{E}-11$ \\
XF2 & 2.45 & $1.18 \mathrm{E}-10$ \\
XF5 & 3.46 & $1.88 \mathrm{E}-5$ \\
XF10 & 7.47 & $2.64 \mathrm{E}-1$ \\
\hline
\end{tabular}

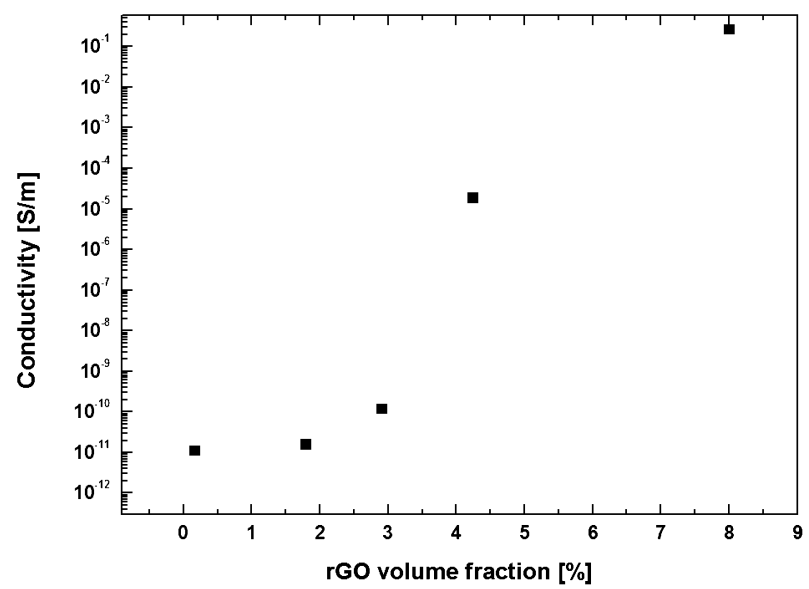

Fig. 11. Electrical conductivity of the hot-pressed $\mathrm{rGO} / \mathrm{Si}_{3} \mathrm{~N}_{4}$ samples as a function of the volume fraction of the rGO phase.
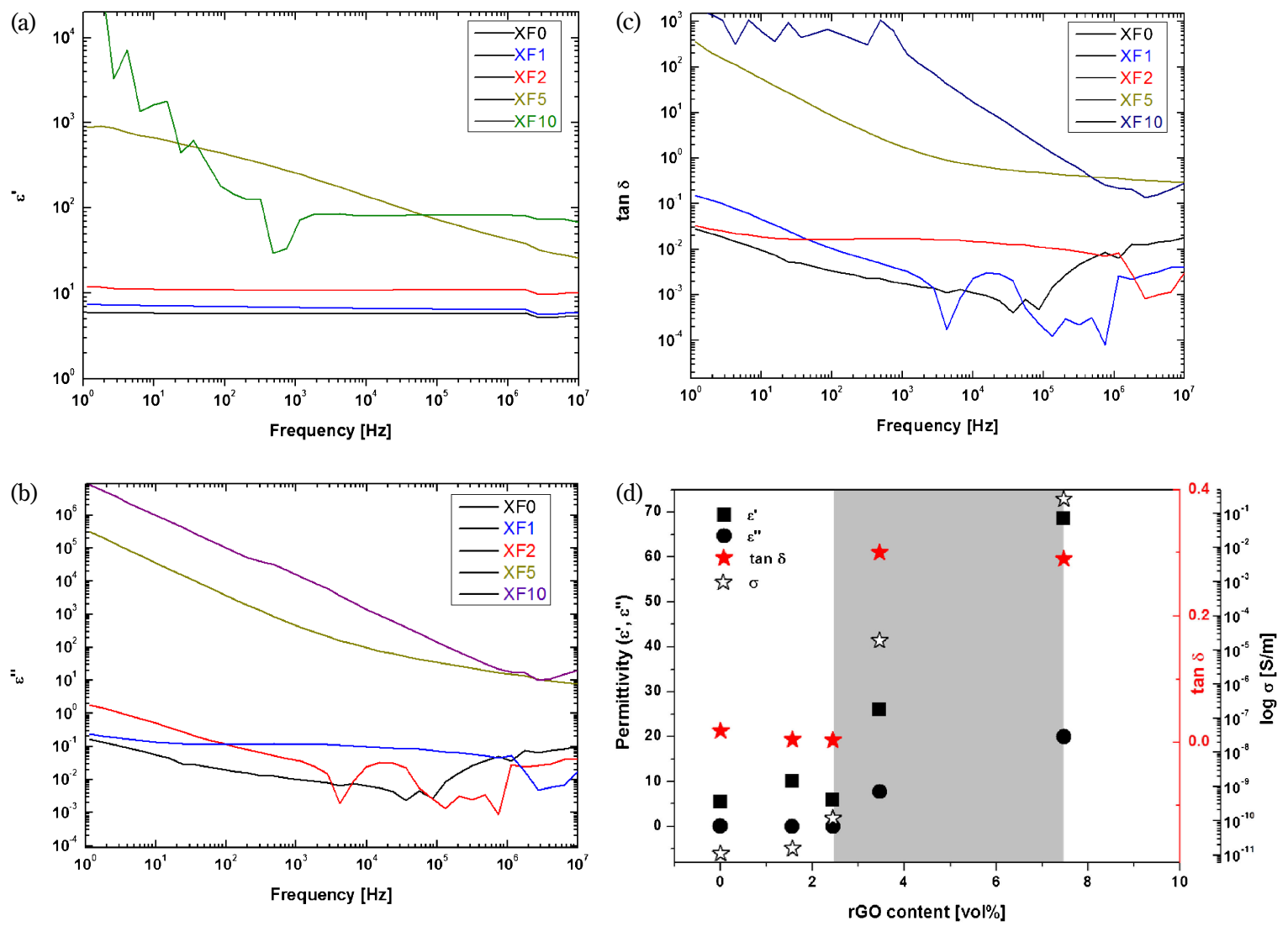

Fig. 12. Real (a) and imaginary (b) parts of the permittivity ( $\varepsilon^{\prime}$ and $\varepsilon^{\prime \prime}$, respectively) as well as the dielectric loss tan $\delta$ (c) of the hot-pressed $\mathrm{rGO} / \mathrm{Si}_{3} \mathrm{~N}_{4}$ monolithic samples as functions of the frequency; d) Real permittivity and dielectric loss (values as for $10 \mathrm{MHz}$ ) as well as the dc electrical conductivity of the $\mathrm{rGO} / \mathrm{Si}_{3} \mathrm{~N}_{4}$ monolithic samples as function of the rGO volume fraction - the grayish area represents the probable region of the percolation threshold in $\mathrm{rGO} / \mathrm{Si}_{3} \mathrm{~N}_{4}$.
$10^{7} \mathrm{~Hz}$ ). Due to the fact that the frequency range used in this study does not correspond to that responsible for atomic and electronic polarization, their contribution to the dielectric behavior of the samples is frequency independent and negligible. Thus, it is considered that the permittivities measured in this work rely on space charge polarization phenomena. At $10 \mathrm{MHz}$, XF0 shows a real part permittivity value of 5 , which is only slightly smaller than that of pure $\mathrm{Si}_{3} \mathrm{~N}_{4}{ }^{28)}$ Upon incorporating rGO, the permittivity values slightly increase; whereas they significantly increase as the content of rGO reaches $3.46 \mathrm{vol} \%$ (as in XF5). The evolution of the dielectric properties in $\mathrm{rGO} / \mathrm{Si}_{3} \mathrm{~N}_{4}$ as a function of the rGO content shows a typical percolation transition behavior as it was observed for the electrical conductivity [Fig. 12(d)].

Thus, at low rGO loading, the relative permittivity is mainly determined by the insulating silicon nitride matrix. At higher rGO loading, the influence of the semiconducting rGO phase becomes significant and contributes to a significant increase of the permittivity. ${ }^{29)}$ Consequently, the investigated nanocomposites might be described by a parallel resistor-capacitor system ( $\mathrm{rGO}$ and $\mathrm{Si}_{3} \mathrm{~N}_{4}$, respectively), with the rGO phase acting as conductive component. When the concentration of rGO is just below the percolation threshold value, the conductive clusters might form a socalled 'super capacitor network' ${ }^{30}$ ) within the insulating matrix material, leading to large values of the permittivity. Therefore, the real part of the relative permittivity of XF10 is as high as 102 and 68 at 1 and $10 \mathrm{MHz}$, respectively.

Near the percolation threshold value, conductor-insulator composites exhibits an intensive increase of the dielectric constant. ${ }^{31)}$ As shown in Fig. 12(d), the value of $\varepsilon^{\prime}$ in XF0, XF1 and XF2 
almost remained unchanged, while the value for XF10 is one order of magnitude larger at $10 \mathrm{MHz}$. A similar trend has been observed for $\varepsilon^{\prime \prime}$, as the value for XF10 at $10 \mathrm{MHz}$ is several orders of magnitude higher than that of XF2. This result suggests that the percolation threshold of the $\mathrm{rGO} / \mathrm{Si}_{3} \mathrm{~N}_{4}$ composites might be located between XF5 and XF10 and thus is in agreement with the electrical conductivity data.

XF5 and XF10 also show high values for the imaginary part permittivity and for dielectric loss while XF0, XF1 and XF2 have small values of $\varepsilon^{\prime \prime}$ and $\tan \delta$. Thus, XF0, XF1 and XF2 are expected to exhibit a transparent behavior towards electromagnetic waves. Whereas XF5 should behave rather as an EM absorbing material and XF10 as an EM shielding material.

Considering the values of the real and imaginary permittivity as well as those of the dielectric loss, the dielectric properties of the prepared $\mathrm{rGO} / \mathrm{Si}_{3} \mathrm{~N}_{4}$ nanocomposites can be influenced by adjusting the rGO content and thus the presented nanocomposites are expected to show different behavior toward electromagnetic waves (EMW), depending of their rGO content.

\section{Conclusion}

The present work emphasizes a facile preparative access to $\mathrm{rGO} / \mathrm{Si}_{3} \mathrm{~N}_{4}$ nanocomposites from a polysilazane filled with different volume fractions of GO. Due to the fact that the synthesis of the polysilazane is performed in the presence of GO, the graphene-based phase is homogeneously dispersed within the microstructure of the resulting $\mathrm{rGO} / \mathrm{Si}_{3} \mathrm{~N}_{4}$ nanocomposites. Measurements of the $\mathrm{dc}$ and ac conductivity of monolithic $\mathrm{rGO} /$ $\mathrm{Si}_{3} \mathrm{~N}_{4}$ samples indicate that the percolation threshold might be located between 2 and 7 vol\% rGO. The prepared nanocomposites exhibit interesting dielectric properties which can be easily tuned upon adjusting their volume fraction of rGO.

Acknowledgements Prof. Ralf Riedel (TU Darmstadt) is gratefully acknowledged for valuable discussions and continuous support. The authors acknowledge the financial support from European Commission through the Marie-Curie ITN project "Functional Nitrides for Energy Applications, FUNEA" (FP7-PITN-GA-2010264873) as well as from the R\&D Convergence Program of MSIP (Ministry of Science, ICT and Future Planning) and NST (National Research Council of Science \& Technology) of Republic of Korea (Grant: CMIP-13-4-KIMS). Also funding within the frame of a Joint Research Project between Japan (JSPS-Japan Society for the Promotion of Science) and Germany (DAAD_German Academic Exchange Service) is gratefully acknowledged.

\section{References}

1) J. Huo, L. Wang and H. Yu, J. Mater. Sci., 44, 3917-3927 (2009).

2) J. Wu and D. D. L. Chung, Carbon, 40, 445-447 (2002).

3) P. C. P. Watts, W. K. Hsu, A. Barnes and B. Chambers, $A d v$. Mater., 15, 600-603 (2003).

4) R. Riedel, G. Mera, R. Hauser and A. Klonczynski, J. Ceram. Soc. Japan, 114, 425-444 (2006).

5) L. S. Walker, V. R. Marotto, M. A. Rafiee, N. Koratkar and
E. L. Corral, ACS Nano, 5, 3182-3190 (2011).

6) K. Wang, Y. F. Wang, Z. J. Fan, J. Yan and T. Wei, Mater. Res. Bull., 46, 315-318 (2011).

7) Y. Fan, L. Wang, J. Li, J. Li, S. Sun, F. Chen, L. D. Chen and W. Jiang, Carbon, 48, 1743-1749 (2010).

8) A. Dimiev, D. Zakhidov, B. Genorio, K. Oladimeji, B. Crowgey, L. Kempel, E. J. Rothwell and J. M. Tour, ACS Appl. Mater. Interfaces, 5, 7567-7573 (2013).

9) D. C. Marcano, D. V. Kosynkin, J. M. Berlin, A. Sinitskii, Z. Sun, A. Slesarev, L. B. Alemany, W. Lu and J. M. Tour, ACS Nano, 4, 4806-4814 (2010).

10) H. He, J. Klinowski, M. Forster and A. Lerf, Chem. Phys. Lett., 287, 53-56 (1998).

11) S. J. Mu, Y. C. Su and H. B. Tang, Chin. Phys. Lett., 30, 096101 (2013).

12) E.-Y. Choi, T. H. Han, J. Hong, J. E. Kim, S. H. Lee, H. W. Kim and S. O. Kim, J. Mater. Chem., 20, 1907-1912 (2010).

13) H.-K. Jeong, Y. P. Lee, M. H. Jin, E. S. Kim, J. J. Bae and Y. H. Lee, Chem. Phys. Lett., 470, 255-258 (2009).

14) C. Chen, Q.-H. Yang, Y. Yang, W. Lv, Y. Wen, P.-X. Hou et al., Adv. Mater., 21, 3007-3011 (2009).

15) R. J. Seresht, M. Jahanshahi, A. M. Rashidi and A. A. Ghoreyshi, Iranica Journal of Energy and Environment (IJEE), 4, 53-59 (2013).

16) S. H. Huh, "Physics and Applications of Graphene - Experiments", Mikhailov S., Editor (2011) InTech. p. 73-90.

17) A. C. Ferrari, J. C. Meyer, V. Scardaci, C. Casiraghi, M. Lazzeri, F. Mauri et al., Phys. Rev. Lett., 97, 187401 (2006).

18) G. Mera, A. Navrotsky, S. Sen, H. J. Kleebe and R. Riedel, J. Mater. Chem., 1, 3826-3836 (2013).

19) F. Tuinstra and J. L. Koenig, J. Chem. Phys., 53, 1126-1130 (1970).

20) D. S. Knight and W. B. White, J. Mater. Res., 4, 385-393 (1989).

21) N. Larouche and B. L. Stansfield, Carbon, 48, 620-629 (2010).

22) A. Cuesta, P. Dhamelincourt, J. Laureyns, A. Martinez-Alonso and J. M. D. Tascon, J. Mater. Chem., 8, 2875-2879 (1998).

23) T. Kuzuba, K. Kijima and Y. Bando, J. Chem. Phys., 69, 40-42 (1978).

24) H. J. Kleebe and Y. D. Blum, J. Eur. Ceram. Soc., 28, 10371042 (2008).

25) G. Mera, R. Riedel, F. Poli and K. Muller, J. Eur. Ceram. Soc., 29, 2873-2883 (2009).

26) A. Sawaguchi, K. Toda and K. Niihara, J. Am. Ceram. Soc., 74, 1142-1144 (1991).

27) S. Stankovich, D. A. Dikin, G. H. B. Dommett, K. M. K. E. J. Zimney, E. A. Stach, R. D. Piner, S. T. Nguyen and R. S. Ruoff, Nature, 442, 282-286 (2006).

28 W. Xiao, P. Xiao, H. Luo, W. Zhou and Y. Li, J. Mater. Sci.: Mater. Electron., 25, 4088-4094 (2014).

29) D. Stauffer and A. Aharony, "Introduction to Percolation Theory", ed. Taylor and Francis (1994).

30) J. W. Xu and C. P. Wong, Dielectric Behavior of Ultrahigh-k Carbon Black Composites for Embedded Capacitor Applications. in Electronic Components and Technology Conference.

31) C. Pecharromun and J. S. Moya, Adv. Mater., 12, 294-297 (2000). 